\title{
Concepção Crítico-Emancipatória e Mídia-Educação: uma interlocução possível à Educação Física Escolar
}

Rafael de Gois Tinôco a,b,c (D); Allyson Carvalho de Araújo ${ }^{d}$ (D)

Keywords:

Education; School; Philosophy;

Audiovisual Media.

\begin{abstract}
This writing was born from the concern about the uses of media apparatus in school, especially in Physical Education classes. It aims to present reflections on the possible dialogue between the Critical- Emancipatory conception and the Media-Education in pedagogical practice, revealing their proximity and possibilities. Methodologically, it is an exploratory documentary study with a qualitative approach, justified by the need to build new proposals in the face of new ways of reading, seeing, thinking and learning. In the end, we build the importance of materializing plans that use such theories, in order to ensure a critical and creative experience, enjoyment, analysis and creation.
\end{abstract}

\section{RESUMO}

Este escrito nasceu da inquietação sobre os usos dos aparatos midiáticos na escola, em especial, nas aulas de Educação Física. Tem como objetivo, apresentar reflexões sobre a possível interlocução da concepção Crítico-Emancipatória e a Mídia-Educação na prática pedagógica, revelando suas proximidades e possibilidades. Metodologicamente, trata-se de um estudo documental exploratório de abordagem qualitativa, justificando-se a partir da necessidade de construção de novas propostas frente aos novos modos de ler, ver, pensar e aprender. Ao final, edificamos a importância da materialização de planejamentos que utilizem tais teorias, a fim de assegurar uma experiência crítica e criativa, fruição, análise e criação.

\begin{abstract}
Resumen
Este escrito nació de la inquietud acerca de los usos de los aparatos de medios en la escuela, especialmente en las clases de educación física. Su objetivo es presentar reflexiones sobre el posible diálogo entre la concepción crítico-emancipadora y la educación mediática en la práctica pedagógica, revelando su proximidad y posibilidades. Metodológicamente, es un estudio documental exploratorio con un enfoque cualitativo, justificado por la necesidad de construir nuevas propuestas frente a nuevas formas de leer, ver, pensar y aprender. Al final, construimos la importancia de materializar planes que usen tales teorías, para garantizar una experiencia crítica y creativa, disfrute, análisis y creación.
\end{abstract}

Palabras clave: Educación; Escuela; Filosofía; Medios Audiovisuales.

\footnotetext{
a Faculdade Maurício de Nassau (UNINASSAU), Centro de Ciências da Saúde (CCS), Departamento de Educação Física (DEF), Natal, Rio Grande do Norte, RN, Brasil.

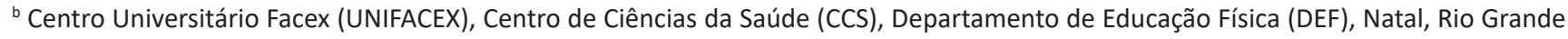
do Norte, RN, Brasil.

c Secretaria de Estado da Educação, da Cultura, do Esporte e do Lazer (SEEC), Natal, Rio Grande do Norte, RN, Brasil.

d Universidade Federal do Rio Grande do Norte (UFRN) Centro de Ciências da Saúde (CCS), Departamento de Educação Física (DEF), Programa de Pós-Graduação em Educação Física (PPGEF), Natal, Rio Grande do Norte, RN, Brasil.
}

Autor correspondente:

Rafael de Gois Tinôco

E-mail: rafaeldegois@hotmail.com

Recebido em 28 de Abril de 2020; aceito em 13 de Junho de 2020. 


\section{INTRODUÇÃO}

$\mathrm{Na}$ atual conjuntura social, somos bombardeados a todo instante por informações advindas da mídia. Esse processo vem se modificando ao longo dos anos e junto aos avanços tecnológicos e a massificação deste mercado, segue transformando a vida das pessoas. Diante disso, novas formas de interação se edificam e o tempo, o lugar e o espaço mudaram de significado. Hoje, o panorama midiático se revela a partir das mais variadas formas de uso, de conteúdo e de comunicação, em que os espaços físicos e virtuais atuam lado a lado. Portanto, as mudanças tecnológicas influenciam nosso modo de viver como seres sociais. Embora nem todos ainda tenham acesso a esses avanços, é preciso reconhecer que as novas tecnologias revolucionaram a comunicação, difundiram a informação, modificaram processos de trabalhos e imprimiram novas formas de pensar e fazer educação. Nesse aspecto, a escola não está aquém dessas influências, sendo também atacada pelas diversas informações que alcançam seus atores. Desse modo, o ambiente escolar caracteriza-se como um lugar de encontro de sistemas simbólicos e culturais, construindo uma complexa rede de tessituras da sua cultura com a cultura midiática. Sobre isso, Araújo et al. (2013, p.114) dizem:

Se antes os registros de nossa construção cultural dependiam da oralidade e de signos rudimentares grafados, agora as possibilidades talvez estejam acima das nossas possibilidades de consumo. O rádio, a televisão, o cinema, o telefone (ou smartphone), o computador, as revistas, os jornais. Isso para pensar nos suportes. Se fôssemos focar em formatos e conteúdos, teríamos nós uma incrível dificuldade de citar um conjunto de exemplos que fosse minimamente representativo. Contudo, cabe dizer que as formas de consumir informações que dizem respeito a nossa construção cultural são tão variadas, que estamos em um momento em que a indústria midiática tem buscado a estratégia de convergência de formatos.

Assim, é possível assegurar que nessas transformações, a educação sai do âmbito escolar e também perpassa por: praças, shoppings, cinemas, clubes, mídias etc., exigindo dos educadores, a compreensão de que nesses lugares se produz cultura e circula determinado aprendizado. Nessa lida, os docentes devem levar em consideração tais conhecimentos adquiridos pelos estudantes, bem como os suportes pelos quais eles utilizaram para isso, os levando à escola como possibilidades educacionais.

Independente da forma como é consumida pelos alunos, especificamente na Educação Física (EF), é fundamental problematizar os conceitos padronizados que urgem dos discursos midiáticos. Faz-se necessário ampliar o debate desses aspectos, concordando com a ideia de Tufte e Christensen (2009, p.113) de que "[...] a cultura das mídias na vida cotidiana precisa ser integrada ao currículo escolar, apoiando o desenvolvimento das práticas pedagógicas em mídia-educação", formando cidadãos com um olhar mais crítico-reflexivo frente a esses discursos.

Considerando a relação EF e mídia, quando afirmamos da importância para os alunos do poder crítico, da tomada de consciência e do seu ativismo social, automaticamente nos remetemos às concepções de ensino das Pedagogias Críticas da EF, tais como: Aulas Abertas (AA) (Hildebrandt; Laging, 1986); CríticoSuperadora (CS) (Coletivo de Autores, 1992); CríticoEmancipatória (CE) (Kunz, 1991, 1994), que buscaram superar o modelo tradicional, que mantém o professor como o detentor do conhecimento e protagonista, com aulas esportivizadas, diretivas, mecanizadas e focadas nos mais habilidosos. Dessa forma, essas pedagogias criticam o viés apenas de saúde, biológico e objetivo, até então, da área, conferindo também o caráter humano, social e subjetivo. Ou seja, dando vazão à EF não só dentro das Ciências da Saúde, mas assim como nas Ciências Sociais e Humanas. Nesse sentido, acompanha uma lógica que se vincula às transformações sociais, políticas e econômicas, visando a superação de desigualdades sociais.

Tais concepções, de forma geral, têm por intenção, a partir da análise da função social da educação, e da EF em particular, a materialização de um ensino crítico-reflexivo, transformador, dialógico, autônomo e emancipador, colocando o aluno como principal agente das aulas e o professor como mediador (Bracht, 1999). Destarte, mesmo reservando atenção e apreço pelas abordagens críticas da EF, nos debruçaremos apenas sobre a concepção CE, proposta por Elenor Kunz (1991, 1994). No rastro dela, o movimentar-se humano é entendido como uma forma de comunicação com o mundo e as proposituras adotadas apontam em direção ao desenvolvimento nos educandos da capacidade de analisar e agir criticamente nesse âmbito.

Logo, foi necessário à EF buscar abordagens mais crítico-reflexivas em suas aulas e formas diferenciadas de ensinar, fugindo do modelo tradicional, assim como a utilização de abordagens mais próximas aos estudantes, oportunizando que as vivências fossem espaço de criação de sínteses de aprendizagens. Neste sentido, os produtos e conteúdos midiáticos se apresentam legitimamente como elementos privilegiados para estabelecer esse diálogo.

Então, o objetivo aqui postulado é o de apresentar reflexões sobre a possível interlocução da concepção $\mathrm{CE}$ com a Mídia-Educação (ME) na prática pedagógica da EF escolar, revelando suas proximidades ao erigir pontos convergentes em suas bases teórico- metodológicas. 
Metodologicamente, trata-se de um estudo documental exploratório de abordagem qualitativa, tendo como alicerce explorar as duas principais obras do Elenor Kunz $(1991,1994)$ no contraponto com a produção acadêmica da ME, Mônica Fantin (2006, 2011), justificando-se a partir da necessidade de construção de novas propostas pedagógicas às aulas frente aos novos modos de ler, ver, pensar e aprender na escola, na tentativa de caminhar para além das concepções típicas de ensino da EF. Como outra questão importante, este estudo avança e colabora com o pensamento de Costa e Wiggers (2013, 2016) que também propôs essa relação, assim como Mendes e Pires (2009), e Pires (2010).

\section{CONCEPÇÃO CRÍTICO-EMANCIPATÓRIA E MÍDIA- EDUCAÇÃO: CONVERGÊNCIAS À PRÁTICA PEDAGÓGICA DA EDUCAÇÃO FÍSICA}

A realização de um recorte tão particular sobre a relação da concepção CE com a ME no âmbito da EF surge da emergência dessa possibilidade em sua prática pedagógica e foi um trabalho bastante meticuloso. Dessa maneira, é necessário contextualizar conceitualmente as teorias citadas na intenção de fazer brotar os pontos convergentes e as alternativas de materialização de propostas à EF.

Nesse interim, começaremos tratando da concepção proposta por Kunz, a saber: CE. Esta concepção foi apresentada, primeiramente, em 1991, na obra "Educação Física: ensino \& mudança" e foi mais bem discutida em 1994, na obra "Transformação didático- pedagógica do esporte". Essa pedagogia de ensino teve influências, principalmente, da Teoria Crítica da escola de Frankfurt e da Fenomenologia.

A principal preocupação dessa abordagem está em "[...] anunciar e estimular mudanças reais e concretas, tanto na concepção de ensino, de conteúdo e de método, como nas suas condições de possibilidade, na prática pedagógica" (Kunz, 1994, p.6). O autor afirma que as duas concepções críticas que antecederam a sua o auxiliaram na construção da $\mathrm{CE}$, pois as $\mathrm{AA}$ avança no modo de tratar o esporte e o aspecto co-educativo e a CS avança nas questões epistemológicas e metodológicas, assim como em seus interesses relacionados aos conhecimentos que serão trabalhados e como serão transmitidos.

Porém, ambas deixaram a desejar em alguns aspectos que precisam ser criticados. Para AA: (1) detalhar a maneira de como devem ser estruturados os programas de ensino em longo prazo e para diferentes grupos; (2) apontamentos mais claros sobre as relações entre os diversos momentos no processo ensinoaprendizagem dos esportes. Já à CS: (1) reforço da visão dicotômica entre corpo e mente pela expressão cultura corporal (Kunz, 1994).

Nesse sentido, a CE rompe com esse dualismo a partir do diálogo com a Fenomenologia, como sendo uma possibilidade de compreender melhor o objeto de estudo da $E F$, pois o ser humano como ser-no-mundo é sempre presença corporal, o ato de pensar é tão corporal quanto o ato de correr, não podendo haver distinção. Dessa forma, Kunz (1994, p.68) defende um novo objeto de estudo, a "Cultura de Movimento", qual seja todas as atividades do movimento humano no esporte e no sentido amplo dele e "[...] que pertencem ao mundo do se-movimentar humano, o que o homem por esse meio produz ou cria, de acordo com a sua conduta, seu comportamento, e mesmo as resistências que se oferecem a essas condutas e ações [...]".

Além disso, para o autor, a percepção, as emoções e os sentimentos são fundamentais para compreender o "se-movimentar" e sua relação com o mundo vivido. A percepção, a sensibilidade e a intuição humana são fatores da fenomenologia relevantes a essa compreensão, em que a percepção do movimentar-se oportuniza a melhoria da qualidade desse movimento no tempo e espaço, a sensibilidade ocupa-se com os objetos, os outros e consigo mesmo e a intuição promove ao ser humano sentir de forma antecipada os resultados esportivos, além de nossa presença corporal na atividade (Kunz, 2000).

Com essa noção, esta concepção também recebe influência da Teoria Crítica da escola de Frankfurt, em especial, de Habermas e a sua teoria do "agir comunicativo", pois uma teoria que se diga pedagógica no viés crítico-emancipatório precisa, segundo Kunz (1994, p.31), na prática:

[...] estar acompanhada de uma didática comunicativa, pois ela deverá fundamentar a função do esclarecimento e da prevalência racional de todo agir educacional. E uma racionalidade com sentido do esclarecimento implica sempre uma racionalidade comunicativa. Devemos pressupor que a educação é sempre um processo onde se desenvolvem "ações comunicativas". O aluno enquanto sujeito do processo de ensino de ser capacitado para sua participação na vida social, cultural e esportiva, o que significa não somente a aquisição de uma capacidade de ação funcional, mas a capacidade de conhecer, reconhecer e problematizar sentidos e significados nesta vida, através da reflexão crítica.

Então, a partir dessa evidenciação crítico-reflexiva, a concepção CE mostra seus fins, no caso, ir além do esporte e da própria $E F$, consentindo com um aspecto interdisciplinar e crítico. Anuindo com a CS, as críticas da CE também afetam a escola de um modo geral, pois esta, junto ao seu ensino, deve materializar uma educação libertadora baseada no diálogo, 
conhecendo e reconhecendo o mundo vivido do aluno e o compreendendo como sujeito de sua própria ação. Logo, os pressupostos freirianos aqui emergem, pois Freire (2013) atestava que para o homem não bastava viver apenas no mundo, mas sim, estar nele, dialogando, interagindo, se apropriando e transformado a cultura. A liberdade "[...] é a matriz que atribui sentido a uma prática educativa que só pode alcançar efetividade e eficácia na medida da participação livre e crítica dos educados" (Freire, 2013, p.6).

O autor ainda destaca que só é possível o desenvolvimento dos pressupostos da sua concepção através de 3 níveis de competência: (1) objetiva; (2) social; (3) comunicativa. A primeira diz respeito aos conhecimentos peculiares do sujeito, e à $E F$, seria o aprender as habilidades práticas. Já a segunda, sinaliza compreender as relações sociais e culturais dos sujeitos e os papeis declarados por eles diante os conhecimentos da EF. E a terceira, versa sobre a necessidade de desenvolver variadas formas de linguagem, dentre elas: oral, corporal, midiática, artística etc., levando em conta que o saber se comunicar e compreender a comunicação dos outros são ações reflexivas, que desencadeiam o pensamento crítico (Kunz, 1994 apud Costa; Wiggers, 2016). Logo, este último nível de competência abre a possibilidade para que os educandos desenvolvam outras formas de linguagem na EF que não só a corporal, fomentando novas maneiras de discutir e problematizar seus conteúdos.

Para Kunz (1994), o desenvolvimento da competência comunicativa deve trazer ao educando a capacidade de leitura crítica do esporte. Desse modo, a forma de saber que leva à emancipação é, então, um saber crítico que tem origem no mundo vivido dos indivíduos passando pelo desenvolvimento de um saber elaborado pelo processo interativo e comunicativo num contexto livre de coerções ou falsas consciências.

Portanto, essa competência exerce um papel fundamental, pois está relacionada ao saber comunicar-se e entender a comunicação dos outros, num processo reflexivo, desencadeando, de forma objetiva, iniciativas do pensar crítico, devendo prevalecer não apenas a linguagem dos movimentos, como também outras formas de linguagem.

Esta concepção ainda apresenta, rumo à transformação didático-pedagógica do esporte e a organização didática das aulas de EF, 3 categorias:

(1) trabalho; (2) interação; (3) linguagem. Sendo a primeira relacionada à competência objetiva e preconiza à aprendizagem técnica; a segunda atrelada à competência social e está caracterizada no debate das relações socioculturais, na apreensão dos papéis sociais e no agir solidário e cooperativo; a terceira aludida à competência comunicativa e possui o papel decisivo à educação crítico-emancipatória, no tocante às linguagens verbal e de movimento (Kunz, 1994 apud Costa; Wiggers, 2016).

De acordo com as categorias mencionadas, Kunz (1994) diz que a linguagem desabrocha como a que faz uma dialógica ao estudante e o proporciona transcender o contexto esportivo, destinando-se ao desenvolvimento de suas capacidades de criação, exploração, discernimento e julgamento de modo crítico.

Sendo assim, é fundamentado nesses aportes da concepção $C E$ que acreditamos no entrelaçamento desta com a ME no fazer pedagógico à $E F$, pois quando falamos dos 3 níveis de competência da CE, percebemos que a última promove o desenvolvimento de várias formas de linguagem que não apenas a corporal para o processo crítico-reflexivo (Kunz, 1994). Logo, essa competência abre espaço à linguagem midiática.

Já quando tratamos dos 3 níveis de organização didática da $C E$, notamos que o último pronuncia o formato em que as sistematizações das práticas devem se orientar, de maneira que seja possível ir para além da linguagem corporal, tradicionalmente mais usada nas aulas. Nessa perspectiva, outras linguagens podem ser usadas ao passo que declarem o pensamento dos educandos quando submetidos às práticas, por isso, dignifica-se esta categoria a contemplação da ampliação da capacidade crítica e criadora dos alunos, em que mais uma vez se confere a linguagem midiática. Nessa perspectiva, a compreensão de convergência entre a concepção CE e a ME segue o entendimento do "agir comunicativo", pois devemos presumir que a educação é sempre um processo de "ações comunicativas", em que: "A capacidade comunicativa não é algo dado, simples produto da natureza, mas deve ser desenvolvida" (Kunz, 1994, p.31). Isto é, na ótica teórico-metodológica e no fazer docente, é de suma importância a materialização de ações comunicativas, porque serão estas que irão oportunizar vivências emancipadoras.

Desse jeito, quando se propicia ao estudante a sistematização por meio das mais diversas linguagens, fomentamos sua competência crítica. É esse tipo de competência que a CE tenciona, pois é primordial tornar os sujeitos emancipados, para que pensem autonomamente e coletivamente. Destarte, é aí que encontramos a ligação desta concepção com a ME. Aqui, mais uma vez, brota a influência do pensamento freiriano. Não só no corpo teórico da $\mathrm{ME}$, mas em parte significativa das operações epistêmicas no campo da comunicação o pensamento de Paulo Freire está presente, ao entender-se que "[...] o primeiro aporte inovador da América Latina à teoria da comunicação produziu-se no e a partir do campo da educação: a pedagogia de Paulo Freire" (Martin-Barbero, 2014, p.17). 
Nesse caso, abordando brevemente a historicidade da ME, a partir de Bévort e Belloni (2009), percebemos que seu início perpassa pelas décadas de 50-60 na Europa, Estados Unidos e Canadá, em que se apresentava a temáticas ligadas à política, ética e ideologia.

O conceito de "Mídia-Educação" ou "educação para as mídias" surge nos discursos dos órgãos internacionais nos anos 60, em especial nos da Organização das Nações Unidas para a Educação, a Ciência e a Cultura (UNESCO), atribuindo-se ao que compreendemos hoje por educação à distância, pois estavam alicerçados na "[...] capacidade destes novos meios de comunicação de alfabetizarem em grande escala populações privadas de estruturas de ensino e de equipes de pessoal qualificado [...]" (Bévort; Belloni, 2009, p.1085).

Além disso, conforme as autoras, no âmbito internacional, a definição da UNESCO de ME prevalente até a década de 80 separava formalmente o que era $\mathrm{ME}$ do que era Tecnologia Educacional. Com isso, Bévort e Belloni (2009, p.1086) atestam: "Entende-se, a partir de então, por "mídia-educação", a formação para a leitura crítica das mídias em geral, independentemente do suporte técnico (impresso, rádio, cinema, televisão)".

Em 1982, a UNESCO, por meio da Declaração de Grünwald, certificou o importante papel das mídias no sentido da promoção da expressão criativa e da participação ativa dos cidadãos, revelando as potencialidades democráticas dos seus dispositivos. Logo, ratifica-se a necessidade da ME como condição essencial na formação à cidadania, vislumbrando a ideia dela tanto como os meios de comunicação de massa, em que a leitura crítica é fundamental, quanto meio de expressão da opinião e da criatividade. Por isso, a noção de ME como formação à apropriação e utilização das mídias como ferramenta pedagógica ao professor e de criação aos cidadãos começa a ser alicerçada (Bévort; Belloni, 2009).

No ano de 1999, com as mudanças tecnológicas do final do Séc. XX, acontece a Conferência Internacional "Educando para as mídias e para a era digital", promovida pela UNESCO, que se torna um marco internacional na história da ME. Este evento tem sua relevância pois, pela primeira vez, são destacados "[...] como princípios norteadores a consideração das crianças e adolescentes como parceiros efetivos (e não mais apenas como destinatário das ações) na discussão e definição de propostas" (Bévort; Belloni, 2009, p.1092).

Por fim, num evento em comemoração aos 25 anos da Declaração de Grünwald, foi realizado um balanço geral desse processo de construção da ME, em que se revelou uma insatisfação, mesmo com avanços. Então, a fim de promover a ME e mobilizar os agentes, foram postuladas ações prioritárias que se organizaram em 4 eixos: (1) Desenvolvimento de programas integrados em todos os níveis de ensino; (2) Formação de professores e a sensibilização dos diferentes atores da esfera social; (3) Pesquisa e suas redes de difusão; (4) Cooperação internacional em ações. Estas recomendações constituem a Agenda de Paris de 2007, que confirma a ME na formação à cidadania, sendo imprescindível para que "[...] a sociedade da informação seja plural, inclusiva e participativa [...]" (Bévort; Belloni, 2009, p.1096).

Desse modo, para Belloni (2009), a ME, ao nascer a partir do contexto das Tecnologias de Informação e Comunicação (TIC's), em que essas entendem que o avanço tecnológico dos aparatos comunicacionais, ao adentrarem de forma tão profunda em todos os espaços sociais, acabaram os tornando objeto de estudo com característica interdisciplinar, assesta à necessidade de integração das TIC's no âmbito escolar através de dois aspectos fundamentais: "objeto de estudo", possibilitando às crianças e aos jovens formas de dominar essa linguagem; "ferramenta pedagógica", viabilizando, aos professores, recursos competentes à melhoria do ensino. Vale lembrar que essas duas dimensões são indissociáveis, porque não podemos atribuir as TIC's somente uma função de instrumento, mas, sobretudo, como objeto de estudo, pois a ME mira à formação do usuário ativo, crítico e criativo das TIC's (Belloni, 2009).

Ainda segundo a autora, as TIC's reúnem duas categorias inseparáveis e que têm servido de dimensões de estudo da área: comunicação educacional e ME. A comunicação educacional objetiva seus estudos no reconhecimento do potencial da mídia como aparato pedagógico enquanto a ME tenciona compreender as mídias como objeto de estudo na educação, ou seja, ambas devem estar atreladas aos processos educacionais. Já Fantin (2006) objetiva transcender essa divisão das TIC's entre "objeto de estudo" e "ferramenta" por meio da análise do primeiro, em que culminou em 3 dimensões: (1) Dimensão instrumental: abarca questões voltadas ao domínio técnico dos aparatos tecnológicos; (2) Dimensão crítica: sugere debates acerca do objeto de estudo (TIC's), rumo a uma reflexão crítica na escola; (3) Dimensão produtiva: utilização das tecnologias como recursos de ampliar e aprimorar o conhecimento dessa área, desenvolvendo o pensamento para além da reprodução, indo ao encontro ao pensamento crítico, assim como a produção midiática. Por isso, a ME para Fantin (2008, p.5) deve ser:

Entendida como a possibilidade de educar para/ sobre as mídias, com as mídias e através das mídias, a partir de uma abordagem crítica, instrumental e expressivo-produtiva. Esta perspectiva de mídiaeducação implica a adoção de uma postura "crítica e criadora" de capacidades comunicativas, expressivas e relacionais para avaliar ética e esteticamente o 
que está sendo oferecido pelas mídias, para interagir significativamente com suas produções, para produzir mídias e também para educar para a cidadania.

Desse modo, as possibilidades de educar com as mídias e as dimensões propostas por Fantin (2008) trazem relações diretas com os níveis de competência de aprendizagem e com as categorias de organização didática da $\mathrm{CE}$, senão vejamos:

Como exemplo declarado dessa conexão em uma prática pedagógica, podemos citar a 4ạ Aula da interlocução proposta pelo autor principal deste escrito em sua dissertação: "EDUCAÇÃO FísICA ESCOLAR \& CINEMA: Experimentando novas formas de ensinar Esporte no Ensino Médio" (2017), em que, resumidamente, os alunos produziram narrativas pelo celular, baseados em 4 roteiros que tratavam do Basquete/Cooperação; do Arremesso de Disco/Doping; do Futebol/Preconceito; da Natação/Deficiência, contemplando a relação: Comunicativa-LinguagemAtravés da mídia-Produtiva. E, durante essa dinâmica, foram ensinadas técnicas de gravação e movimentos dos esportes, considerando a relação: Objetiva- TrabalhoCom a mídia-Instrumental, da mesma maneira como foram debatidas características destes e suas relações com as temáticas sociais, abrangendo a relação: SocialInteração-Para/Sobre a mídia-Crítica.

Então, mesmo as mediações culturais acontecendo de qualquer forma e tempo, as mediações pedagógicas têm por objetivo a instrução dos atores educacionais para uma ação ativa e uma produção responsável, que resulte numa visão mais crítica em relação ao que assistem, acessam, produzem e compartilham. Em virtude disso, "[...] a mídia-educação pode funcionar como instrumento cultural e educativo, tanto no sentido da formação prático-reflexiva dos profissionais da comunicação como na formação e capacitação de educadores" (Rivoltella, 2002, p,35 apud Fantin, 2011, p.33-34).

Pressupondo que as TIC's estão em diversos lugares e espaços, podemos concluir que elas também estão no ambiente escolar e vem alterando, aos poucos, as formas de ensinar. Dessa maneira, as relações entre os atores escolares podem partir para uma proposta interdisciplinar e (re)inovadora. E, se observarmos as
TIC's superando sua instrumentalização, notaremos que, nos dias atuais, há uma ativa participação das pessoas na criação e construção de conhecimento e produção midiática.

Cada vez mais as implicações midiáticas no dia-a-dia vêm se tornando imperceptíveis e, consequentemente, inquestionáveis, muito devido ao excesso informacional que ocorre. Hoje, a informação aparece em demasia e o conhecimento, junto a sua análise crítica, aparece em segundo plano. $E$, devemos considerar que não é pelo fato das pessoas lerem jornais, assistirem TV, navegarem na internet etc. que estão obtendo conhecimento, mas sim, a partir de um olhar mais crítico da realidade e na capacidade de ver e rever as coisas.

Nesse propósito, é notório que a sociedade atual sente a influência midiática em seu cotidiano, muito devido ao alcance e a possibilidade de convergência dos meios de comunicação. Segundo Martin-Barbero (2014, p.66):

A revolução tecnológica que vivemos não afeta apenas individualmente a cada um dos meios, mas produz transformações transversais que se evidenciam na emergência de um ecossistema educativo conformado não só por novas máquinas ou meios, mas por novas linguagens, escritas e saberes.

Dessarte, é legítimo o trato com as tecnologias nas escolas, no intento de preservar o direito dos estudantes a terem acesso aos aparatos midiáticos e a refletirem sobre seus discursos rumo uma educação libertadora. Isto posto, além de possibilitar o contato com tais tecnologias, os professores podem dar sentido pedagógico ao uso, de maneira a fomentar uma ação intencional e organizada daquilo que se propõe como planejamento educativo.

Pensando nisso, a ME se apresenta como importante aliado na configuração dessa educação. 0 professor deve fazer uso das mais variadas formas de ensino e, por consequência, utilizar os mais diversos aparatos e materiais para alcançar seus objetivos.

A mídia-educação é parte essencial dos processos de socialização das novas gerações, mas não apenas, pois deve incluir também populações adultas, numa concepção de educação ao longo da vida. Trata-se de

Quadro 1. Relação dos níveis de competência de aprendizagens e das categorias de organização didática da Crítico-Emancipatória com a possibilidade de educar com as mídias e as dimensões da Mídia-Educação

\begin{tabular}{ccccc}
\hline \multicolumn{2}{c}{ Crítico-Emancipatória } & & \multicolumn{2}{c}{ Mídia-Educação } \\
\cline { 1 - 2 } $\begin{array}{c}\text { Níveis de competência de } \\
\text { aprendizagem }\end{array}$ & $\begin{array}{c}\text { Categorias de organização } \\
\text { didática }\end{array}$ & & Possibilidade de educar & Dimensões \\
\hline Objetiva & Trabalho & & Com a mídia & Instrumental \\
Social & Interação & Para/Sobre a mídia & Crítica \\
Comunicativa & Linguagem & & Através da mídia & Produtiva \\
\hline
\end{tabular}

Fonte: Próprio Autor. 
um elemento essencial dos processos de produção, reprodução e transmissão da cultura, pois as mídias fazem parte da cultura contemporânea e nela desempenham papéis cada vez mais importantes, sua apropriação crítica e criativa, sendo, pois, imprescindível para o exercício da cidadania (Bévort; Belloni, 2009, p.1083).

Portanto, todas as características aqui apresentadas sobre a ME estabelecem relações diretas com os objetivos proclamados pela concepção $\mathrm{CE}$, sobretudo na intenção de buscar, no processo de ensino-aprendizagem, ações que favoreçam a autonomia dos seres através de práticas intencionais que valorizem o discente como protagonista e, por conseguinte, nos modos de atuação docente e discente, em que se faz necessário erigir um novo paradigma no ambiente escolar para esses atores, surgindo o professor "coletivo e multicompetente" e o "estudante autônomo" (Costa; Wiggers, 2016).

Enfim, apesar de ser possível relacionar teoricamente a concepção CE com a ME, ainda se faz necessário refletir sobre como esses aparatos midiáticos influenciam no cotidiano dos indivíduos, no viés de angariar mais elementos à sua problematização e utilização no ambiente escolar.

\section{CONSIDERAÇÕES FINAIS}

Quando tratamos de trabalhos no contexto educacional, com tantas possibilidades de diálogo, novas releituras, novas formas de fazer e novos olhares, nossas considerações finais não poderiam deixar de serem parciais e, a cada ressignifação, novas histórias irão surgir.

Dito isso, tivemos como objetivo deste estudo o de apresentar reflexões sobre a possível interlocução da concepção CE com a ME na prática pedagógica da EF escolar. Parece paradoxal que nos dias de hoje, com todo esse constante avanço tecnológico, estratégias de ensino utilizando a mídia e/ou os aparatos midiáticos ainda sejam postas de maneira secundária na escola. Seria incoerente pensar em emancipação do sujeito fechando as portas aos avanços de uma tecnologia que passou a contribuir na articulação destes. Logo, não seria possível pensar nos ideais democráticos olhando ingenuamente para os processos comunicacionais que exercem influência direta sobre as pessoas.

Nesse sentido, as reflexões aqui colocadas sobre a convergência da concepção CE com a ME na EF potencializam novas construções didáticometodológicas às aulas. Vale ressaltar que a intenção desse estudo não foi superestimar a mídia e seu uso na escola como se a mesma fosse resolver todos os problemas desse espaço, tampouco da EF, mas sim demonstrar sua relevância e fluidez para com as reflexões advindas dos conteúdos escolares por outros vieses que não os historicamente postos. Como contraponto às tradições alarmadas na EF com aulas esportivizadas, mecanicistas, tecnicistas etc., a experiência com a ME pode oportunizar uma reflexão sobre os conteúdos para além do saber fazer e, portanto, com trato pedagógico crítico-reflexivo, fazendo o aluno refletir sobre o mundo que está a sua volta.

Por fim, é necessário perceber, principalmente pelo caráter multidisciplinar da EF, que a prática pedagógica utilizando a temática em questão ainda acontece de forma incipiente e que é preciso mudar esse panorama. Sigamos por esse caminho.

\section{REFERÊNCIAS}

ARAÚJO, Allyson Carvalho de et al. O que se pode aprender numa sala escura: relatos e notas sobre educação e cinema. Atos de Pesquisa em Educação, Blumenau, v.8, n.1, p.111-128, jan./abr. 2013.

Belloni ML. O que é Mídia-Educação. 3. ed. Campinas: Autores Associados; 2009.

Bévort E, Belloni ML. Mídia-educação: conceitos, história e perspectivas. Educação \& Sociedade. 2009;30(109):10811102.

Bracht V. A constituição das teorias pedagógicas da Educação Física. Caderno Cedes. 1999;199(48):69-88.

Coletivo de Autores. Metodologia do ensino da Educação Física. São Paulo: Cortez; 1992.

Costa JM, Wiggers ID. A Mídia-Educação na escola na escola: por um ensino emancipatório em Educação Física. In: Anais da 36. Reunião Nacional da ANPEd; 2013; Goiânia, Brasil. 6. Disponível em: <http://www.anped.org.br/sites/default/ files/gt16_2847_texto.pdf>. Acesso em: 06 jun. 2020.

Costa JM, Wiggers ID. Pedagogia Crítico-Emancipatória e Educação Física escolar: confluências à Mídia Educação. Movimento. 2016;22(2):625-634.

Fantin M. A mídia na formação escolar de crianças e jovens. In: Anais do 31. Congresso Brasileiro de Ciências da Comunicação; 2008; Natal, Brasil. Natal: NP Comunicação Educativa; 2008. 15p. Disponível em: <http://www. intercom.org.br/papers/nacionais/2008/resumos/ R3-0529-2.pdf>. Acesso em: 23 abr. 2020.

Fantin M. Mídia-educação: aspectos históricos e teóricometodológicos. Olhar de professor. 2011;14(1):2740.

Fantin M. Mídia-educação: conceitos, experiências, diálogos Brasil-Itália. Florianópolis: Cidade Futura; 2006.

Freire P. Educação e mudança. 30. ed. Rio de Janeiro: Paz e Terra, 2007.

Freire P. Educação como prática da liberdade. Rio de Janeiro: Paz e Terra, 2013.

Hildebrandt R, Laging R. Concepções abertas no ensino da Educação Física. Rio de Janeiro: Livro Técnico; 1986.

Kunz E. Educação Física: Ensino \& Mudanças. Ijuí: Unijuí; 1991.

Kunz E. Transformação didático-pedagógica do esporte. ljuí: Unijuí; 1994.

Kunz E. Esporte: uma abordagem com a fenomenologia. Revista Movimento. 2000;6(12):19-27. 
Martin-Barbero J. A comunicação na educação. Maria IVL, Dafne M, Tradutoras. São Paulo: Contexto; 2014.

Mendes DS, Pires GL. Desvendando a janela de vidro: relato de experiência escolar de Mídia-Educação e Educação Física. Revista Brasileira de Ciências do Esporte. 2009;30(3):79-94.

Pires GL. A Educação Física e o discurso midiático: abordagem crítico-emancipatória em pesquisa-ação no ensino de graduação. Subsídios para a saúde? Campinas. Tese (Doutorado em Educação Física na área de Ciências do Esporte) - Universidade Estadual de Campinas; 2000.

Rivoltella PC. Media education: modelli, esperienze e profilodisciplinare. Roma: Carocci; 2002.

Tufte B, Christensen O. Mídia-educação - entre a teoria e a prática. Perspectiva. 2009; 27(1):97-118. 


\section{ERRATA}

\section{Errata}

No artigo "Concepção Crítico-Emancipatória e Mídia-Educação: uma interlocução possível à Educação Física Escolar", DOI https://doi.org/10.1590/rbce.42.2020.0037, publicado no periódico Revista Brasileira de Ciências do Esporte, vol. 42, 2020, e2068, são necessárias as seguintes correções:

Na página 01, no nome do segundo autor do artigo, onde se lê:

"Allyson Carvalho de Araújo,a,d"

Leia-se:

"Allyson Carvalho de Araújod"

Na página 1, ao final do segundo parágrafo da coluna da esquerda, há um anúncio de citação direta, onde se lê:

"Autor et al. (2013, p.114)"

Leia-se:

"Araújo et al. (2013, p.114)".

Na página 4, no terceiro parágrafo da coluna da esquerda, onde se lê:

"(Costa; Wiggers, 2016 apud Kunz,1994)"

Leia-se:

"(Kunz, 1994 apud Costa; Wiggers, 2016)"

Também na página 4, no segundo parágrafo da coluna da direita, onde se lê:

"(Costa; Wiggers, 2016 apud Kunz, 1994)"

Leia-se:

"(Kunz, 1994 apud Costa; Wiggers, 2016)"

Na página 6, no final do segundo parágrafo da direita, onde se lê:

"(Fantin, 2011, p.33-34 apud Rivoltella, 2002, p.35)"

Leia-se:

"(Rivoltella, 2002, p,35 apud Fantin, 2011, p.33-34)"

Na página 7, na lista de referências, deve-se inserir a seguinte referência:

ARAÚJO, Allyson Carvalho de et al. O que se pode aprender numa sala escura: relatos e notas sobre educação e cinema. Atos de Pesquisa em Educação, Blumenau, v.8, n.1, p.111-128, jan./abr. 2013. 